\title{
Burn Injury Characteristics and Outcomes among Hospitalized Patients in Tertiary Burn Unit
}

\author{
Bahir Sabah Abood Allawi', HasanAlwan Baiee², Ameer Hasan Baiee ${ }^{3}$ \\ ${ }^{1}$ Lecturer, Dr., Babylon University, College of Medicine/Iraq, ${ }^{2}$ Prof., Dr. Babylon University, Hammurabi College \\ of Medicine/Iraq, ${ }^{3}$ Senior Medical Student, Dr./Babylon University/College of Medicine/Iraq
}

\begin{abstract}
Background: Burn Injuries constituted an important high priority health problem especially in little and medium salary republics including Iraq.

Objective: Identify the characteristics of burn injuries and its outcomes among patients admitted to Al-Hilla Teaching Hospital burn unit-Babylon Province Iraq.

Method: This was observational cross sectional hospital based study, burn injury data were collected from the interview of burn patients admitted to burn unit of Al Hilla Teaching Hospital,Babylon Province, Iraq during the last four months during the year 2019, using special data collection questionnaire included; burn patients demographic characteristics, period of hospital stay (days), size of total body surface areas, degrees of burn injuries, types of treatment and the outcomes.

Results: The highest proportion of cases were males, the majority of patients were young adults and children, about four fifth of cases were rural dwellers (78\%). The means and standard deviations of duration of hospitalization and total surface areas were 5.72+53 days and 21,9+21.1 respectively, about two thirds of the study group were second and or third degrees burn, only $12 \%$ of patients were treated surgically by wound excision and skin graft, $67 \%$ of patients were cured while the case fatality rate was $9 \%$.
\end{abstract}

Conclusion: Children, males and poorly educated patients were the majority of cases, about nine in tenth were treated conservatively and about two thirds of cases were cured.

Keywords: Burn injuries, Characteristics, outcomes, Babylon Province, Iraq.

\section{Introduction}

Burn is one of the most severe injuries ${ }^{[1]}$ Burns representing a common type of domestic trauma ${ }^{[2]}$. Burn injuries are one of the very important health problems that cause to prolonged hospitalization and hence increased expenses for patients, their families

\footnotetext{
Corresponding Author:

Bahir Sabah AboodAllawi

Lecturer, Dr., Babylon University, College of Medicine/ Iraq

e-mail: qaisajam1981@gmail.com
}

and society ${ }^{[3]}$. Burn injuries are more common in developing countries including Iraq, especially in poor socioeconomic and rural areas ${ }^{[4,5]}$. The number of burn injuries worldwide was very high in 2017 According to the Global Burden of Diseases ${ }^{[6]}$, accidental burn damage is considered the $3^{\text {rd }}$ common reason of death in the USA ${ }^{[7]}$, these injuries have a major economic and psychosocial impacts ${ }^{[8,9]}$. Some countries have made substantial progress in reducing the incidence and mortality of burns by implementing measures related to prevention and treatment ${ }^{[4-6,10-12]}$ that is why during the last decades, an important progress has been made in reducing the morbidity and mortality of burns $[10,13,11,14]$. Burn patients were more often seen during the winter months. Unintentional and intentional burn injuries vary 
across age groups, sex, income and global region but the majority of burn patients were children, young adults and males ${ }^{[12,15]}$. In contrary to low and middle income countries in high-income ones, the trend recently has been a reduction in burn incidence, burn severity, length of hospital stay and mortality rate ${ }^{[13-17,16-20]}$. Research on burn in Iraq were limited, this study was conducted to describe the characteristics and the outcomes of burn injuries among Iraqi hospitalized patients.

\section{Method}

A cross sectional observational descriptive study displayed on peoples admitted at Burn Wards Center in Al Hilla Teaching Hospital - Babylon province Iraq(the only tertiary referral burn center), during the period from the beginning of September through the end of December 2019. Ethical approval was obtained from the ethical committee of Babylon medical college. Data were collected through interviewing patients or their companions after taking their verbal consents. A pretested questionnaire which includes information about demographic characteristics of enrolled patients suffering from burn injuries who admitted to this referral burn center, data included age (years), gender, level of education, place of residence, size of burns using the Lund and Browder chart ${ }^{[18]}$. Most burns are small and superficial (First Degree) involve only the epidermis causing only local injuries. When estimating the degree of burn in this study, only partial thickness and full thickness burns are considered and superficial burns are excluded.

However, burns can be deeper; partial thickness burns (second degree) extend through the epidermis and into the dermis, full-thickness burns (third degree) extend through both the epidermis and dermis and into the subcutaneous fat or deeper ${ }^{[19,20]}$. All patients with burn injury were studied consecutively. No patient was excluded from the study. Descriptive statistics including frequencies, percentages, means and standard deviations were demonstrated in tables and graphs. Inferential statistics (chi square test) were used to detect significant study associations using SPSS version 24 . The P values less than 0.05 were considered significant.

\section{Results}

In this study males to female ratio is $1,2: 1$ this increase in male ratiodoes not reach the statistically significant level $\mathrm{p}>0.05$. [Figure 1].

Figure [2] shows that children and young adults are highly affected by burn injuries, the vast majority of cases are below 30 years of age.

Table [1] reveals that most of the victims are living inrural regions compared to urban dwellers, this difference is highly significant $\mathrm{p}<0.05$.

Table [2] shows the means and standard deviations of the duration of admission and the Total Body Surface areas (TBSA) are 5.72+53 days and 21,9+21.1 respectively. Depicts that the most common group of duration of admission is 1-5 days, which constitutes $(67 \%)$.Table [3], explains the outcomes of cases, $67 \%$ were cured, only 9 cases died (case fatality rate is $9 \%)$. And also show that $(12 \%)$ of cases were treated by wound excision and or skin graft. Table [4] reveals that the high proportion of burns patient have TBSA 10$20 \%$. And also shows that 34\% patients suffer second and or third degree burn injuries.

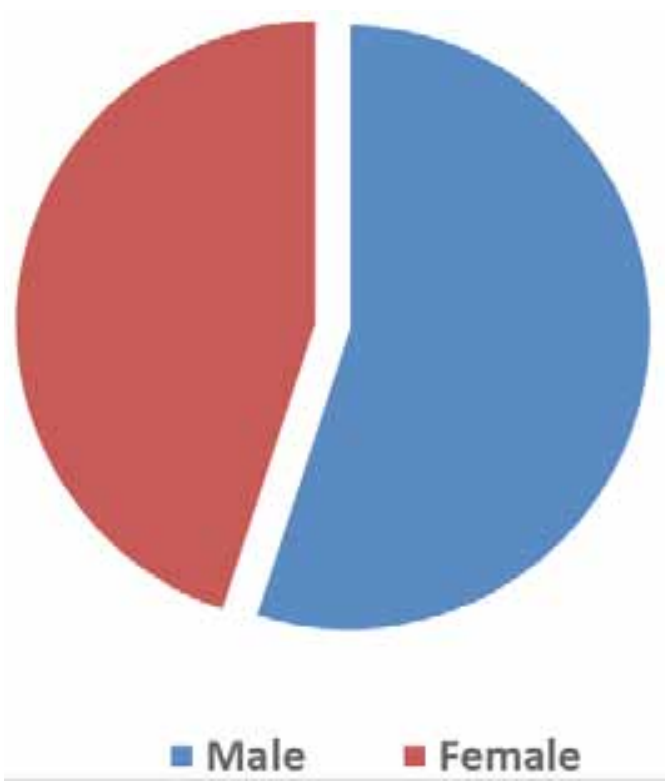

Figure (1): distribution of burn cases by gender (Male to Female Ratio 2:1). 


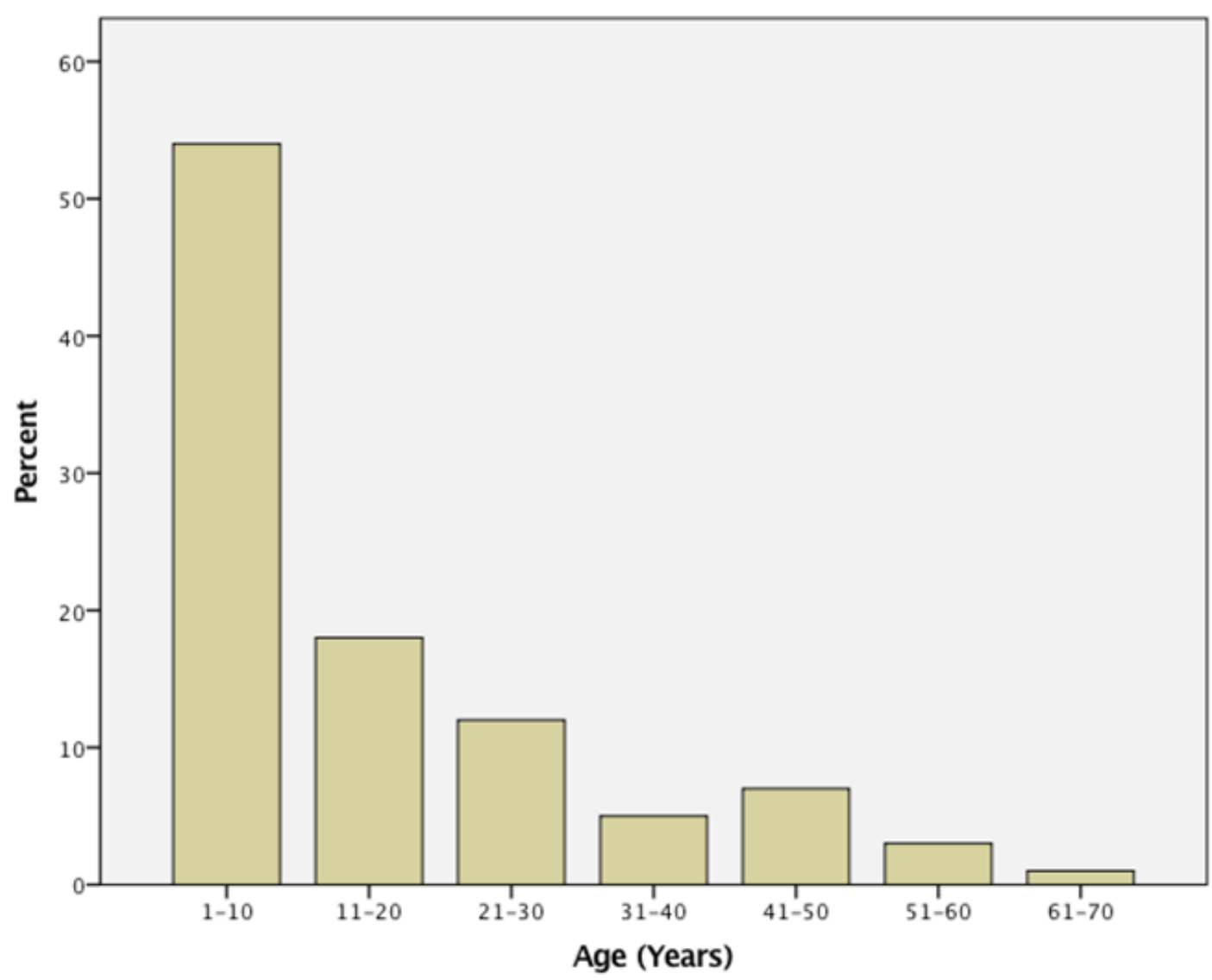

Fig (2): Distribution of the burn injury cases by age group.

Table (1): Distribution of burn cases by place of residence

\begin{tabular}{|l|c|c|}
\hline Place of residence & Frequency & Percentage \\
\hline Rural & 78 & 22 \\
\hline Urban & 22 & 100 \\
\hline Total & 100 & $78)$ \\
\hline
\end{tabular}

The chi-square statistic is 17.0139 . The $\mathrm{p}$-value is .000037 . Significant at $\mathrm{p}<0.05$.

Table 2: Frequency distribution of cases by level of education and duration of admission

\begin{tabular}{|l|c|c|}
\hline Level of Education & Frequency & Percentage \\
\hline Below school & 52 & 52.0 \\
\hline Primary school & 12 & 6.0 \\
\hline Intermediate & 6 & 17.0 \\
\hline Secondary school & 17 & 9.0 \\
\hline Collage & 9 & 4.0 \\
\hline Illiterate & 4 & Percent \\
\hline Duration of stay in the hospital (days) & Frequency & 62.0 \\
\hline $1-5$ & 62 & 24.0 \\
\hline $6-10$ & 24 & 10.0 \\
\hline $11-15$ & 10 & 1.0 \\
\hline $16-20$ & 1 & 2.0 \\
\hline $21-25$ & 2 & 1.0 \\
\hline $30-35$ & 1 & \\
\hline
\end{tabular}


Table 3: Frequency distribution of the study group according to the outcome and the type of treatment.

\begin{tabular}{|l|c|c|}
\hline Outcome & Frequency & Percent \\
\hline Cured & 67 & 37.0 \\
\hline Discharge on his responsibility & 3 & 3.0 \\
\hline Discharge on family responsibility & 16 & 5.0 \\
\hline Referred to another department or hospital & 5 & 9.0 \\
\hline Died(case fatality) & 9 & Percent \\
\hline Treatment & Frequency & 88.0 \\
\hline Conservative & 88 & 12.0 \\
\hline Wound Excision \& Skin Graft & 12 & $100 . \%$ \\
\hline Total & 100 & \\
\hline
\end{tabular}

Table 4: Frequency distribution of the study group according to the Total body surface areas and degree of burn.

\begin{tabular}{|l|c|c|}
\hline Total Body Surface Area & Frequency & Percent \\
\hline Below $10 \%$ & 29 & 29.0 \\
\hline $11-20 \%$ & 39 & 39.0 \\
\hline $21-30 \%$ & 16 & 16.0 \\
\hline $31-40 \%$ & 6 & 6.0 \\
\hline $41-50$ & 2 & 2.0 \\
\hline More than $50 \%$ & 8 & 8.0 \\
\hline Degree of burn & Frequency & Percent \\
\hline 2。 degree burn & 66 & 66.0 \\
\hline 3० degree burn & 8 & 8.0 \\
\hline 2。 \& 3० degree burn & 26 & 26.0 \\
\hline
\end{tabular}

\section{Discussion}

The finding of this study reveals that males are predominantly affected as compared to females but this does not reach the significant statistical difference this finding does not agree with the findings of other researchers ${ }^{[21-28]}$ while other study reported a similar finding in gender composition ratio ${ }^{[29]}$ but our finding disagrees with the findings of other researchers who found that females were suffered burn injuries significantly more than males ${ }^{[30-32]}$. Regarding age of patients, this study clarifies that the vast majority of the victims are below 30 years of age and mainly children below ten years, this result is similar to result reported by other studies ${ }^{[26,33]}$ and this explain why that most of the burn victims were male in gender due to that the boys are more susceptible to burn accidents because they are more active than the girls.

A study conducted by Nthumba on burn patients in sub-Saharan region shows similar finding, where kids aged $\geq 10$ years characterized more than $80 \%$ of the burn persons ${ }^{[26]}$.

The majority of cases in our study were living in rural areas, this finding goes in line with the finding of similar study conducted in Pakistan ${ }^{[32]}$ this may be due to the poor safety awareness of cooking among rural dwellers among others such as the lack of level of domestic safety.

High proportion of burn patients are poorly educated, this finding is in consistent with the finding of local study ${ }^{[28]}$.

The current study reveals that the mean duration of hospital stay of burn patient is 5.7days this finding is close to the finding (7.1days) of similar study conducted on convenient sample of 75 burn patients at Pakistan Institute of Medical Sciences in Islamabad ${ }^{[32]}$ but its lower than the average hospital stay of burn patients studied by Bataineh et al. in north Jordan 16 days ${ }^{[22]}$ and 
this lowest mean duration in the hospital stay compared to the other studies comes from two reasons, the first that we include in this study all the patients including those who discharge within one or few days after admission on the family or their responsibility (19\%) as shown in table 5, and the second reason was related to that the specialist staff policy is to early discharge the patient with low percentage and degree burns to avoid serious complications.

This study identifies that the mean of TBSA among victims is about $22 \%$ which is much lower than that reported by other study conducted at a tertiary burn care center in the National Institute of Burn and Plastic Surgery in Dhaka Bangladesh on 66 hospitalized burn patients which was $46.4 \%{ }^{[32]}$

The proportion ofsecond-degree burns in our study is higher than that reported by local study conducted in the medical city teaching hospital-Baghdad ${ }^{[28]}$.

The case fatality rate among the study group in this study is about one in tenth which is higher than that reported by other study conducted in Jordan ${ }^{[22]}$ but the mortality in our study is lower than what was reported by other study and the cure rate was much higher than what was depicted by Banhansali et al 7.3\% ${ }^{[28]}$.Those who need surgical intervention of some sort once or twice by wound excision and or skin graft in this study are about $12 \%$ which much is less than that reported by Fathallah in Basrah province where about $22.4 \%$ of the studied burn patients were treated by surgical intervention, this difference may be related to the difference in the sample size or the availability of resources required for plastic surgery including trained medical staff ${ }^{[34]}$.

\section{Conclusion}

Children, males and poorly educated patients were the majority of cases, about nine in tenth burn cases were treated conservatively and about two thirds of cases were cured, the case fatality rate is relatively high. There is a strong need to take suitable and effective measures to prevent and control the issue of burn on a national level. Improvement of the quality of health care service in burn center is strongly requested.

Ethical Clearance: The Research Ethical Committee at scientific research by ethical approval of both $\mathrm{MOH}$ and MOHSER in Iraq

\section{Conflict of Interest: Non}

\section{Funding: Self-funding}

\section{References}

1. Yucel Y, Acar HA, Erkal KH, Arditi NB. Retrospective analysis of patients with burn injury treated in a burn center in Turkey during the Syrian civil war. Saudi Med J. 2017 Jan; 38(1): 93-96.doi: 10.15537/smj.2017.1.16448

2. Brusselaers N, Monstrey S, Vogelaers D, Hoste E, Blot S. Severe burn injury in Europe: a systematic review of the incidence,etiology,morbidity and mortality. Critical care. 2010;14(5):R188

3. Mohadeth Ardebili F, BozorgNejad M, Manzari ZS. Burn injury in Mottahari Burn Center in Tehran, Iran. World J PlastSurg 2016;5:77-79

4. Mehrabani D, Farjam M, Geramizadeh B, Tanideh N, Amini M, Panjehshahin MR. The healing effect of curcumin on burn wounds in rat. World $\mathrm{J}$ PlastSurg 2015;4:29-35

5. Vaghardoost R, Kazemzadeh J, Dahmardehei M, Rabiepoor S, Farzan R, Kheiri AA, Khosravy R, Manafi F. Epidemiology of Acid-Burns in a Major Referral Hospital in Tehran, Iran. World J PlastSurg 2017;6(2):170-175

6. GBD 2017 Disease and Injury Incidence and Prevalence Collaborators. Global, regional and national incidence, prevalence and years lived with disability for 354 diseases and injuries for 195 countries and territories, 1990-2017: A systematic analysis for the Global Burden of Disease Study 2017. Lancet. 2018;10159:1789-858.

7. Lee CJ, Mahendraraj K, Houng A, Marano M, Petrone S, Lee R, Chamberlain RS. Pediatric Burns: A Single Institution Retrospective Review of Incidence, Etiology and Outcomes in 2273 Burn Patients (1995-2013).J Burn Care Res. 2016 Nov/ Dec; 37(6):e579-e585

8. Sadeghi-Bazargani H, Maghsoudi H, Ranjbar F, Mashadi-Abdollahi. H. Stress disorder and PTSD after burns injuries: a prospective study of predictors of PTSD at Sina Burn Center, Iran. Neuropsychiatr Dis Treat. 2011; 7: 425- 429.

9. Mohammed AAQ The prevalence of burn related deaths in Basrah. The Medical Journal of Basrah University;2018 36, (1):22-28.

10. Jeschke MG, Peck MD. Burn care of the elderly. J Burn Care Res. 2017;38(3):e625-28.

11. Kraft R, Herndon DN, Al-Mousawi AM, et al. Burn 
size and survival probability in paediatric patients in modern burn care: A prospective observational cohort study. Lancet. 2012;379(9820):1013-21.

12. Kuvandik G, Ucar E, Karakus A. Epidemiology and cost of burns in emergency department during Syrian civil war. Bratisl Med J 2018; 119 (11) 731-73.

13. Aldana MC, Navarrete N. Epidemiology of a decade of Pediatric fatal burns in Colombia, South America. Burns 2015; 41:1587.

14. Smolle C, Cambiaso-Daniel J, Forbes AA, et al. Recent trends in burn epidemiology worldwide: A systematic review. Burns 2017; 43:249.

15. Santos JV, Oliveira A, Costa-Pereira A, et al. Burden of burns in Portugal, 2000-2013: A clinical and economic analysis of 26,447 hospitalisations. Burns 2016; 42:891.

16. Hwee J, Song C, Tan KC, et al. The trends of burns epidemiology in a tropical regional burns center. Burns 2016; 42:682.

17. Saeman MR, Hodgman EI, Burris A, et al. Epidemiology and outcomes of pediatric burns over 35 years at Parkland Hospital. Burns 2016; 42:202.

18. Gillenwater J. \& Garner W. in Grabb and Smith's Plastic surgery by Chung K.C. $8^{\text {th }}$ Edition. Wolters \& Kluwer. 2019; 179

19. Jiang, M. J., Li, Z. \& Xie, W. G. Epidemiological investigation on 2133 hospitalized patients with electrical burns. Zhonghuashaoshangzazhi = Zhonghuashaoshangzazhi $=$ Chinese journal of burns33, 732-737 (2017).

20. Stiles K. Emergency management of burns: part 2. Emerg Nurse. 2018 Jul;26(2):36-41.

21. Othman N, Kendrick D. Epidemiology of burn injuries in the East Mediterranean Region: a systematic review. BMC Public Health;2010;10 (83).

22. Bataineh Z, Alquran T, Al-Balas H, Khammash MR.Pattern of burn injury at north of Jordan. International Journal of Burns and Trauma 2018; $8(1): 1-5$

23. Toppi J, Cleland H, Gabbe B. Severe burns in Australian and New Zealand adults: Epidemiology and burn centre care. Burns. 2019 Sep;45(6):14561461.

24. Wang W, Zhang J, Lv Y, Zhang P, Huang Y, Xiang F .Epidemiological Investigation of Elderly Patients with Severe Burns at a Major Burn Center in Southwest China.MedSciMonit. 2020 Jan 6; 26:e918537.

25. Morgan A, Bin Sultan AM, Al Harbi AM, Aljuhayyim AS, Al Hatlan OA. Aldhfyan Y. Burn Inguries and Associated Causes in AL KHARJ Province of Saudi Arabia : are they preventable ? Int. J. Adv. Res.2017; 5(2), 1885-1891.

26. Nthumba PM. Burns in sub-Saharan Africa: A review. Burns. 2016 Mar;42(2):258-66. doi: 10.1016/j.burns.2015.04.006. Epub 2015 May 14

27. Adejumo PO, Akese MI.A five-year prevalence study of burn injury in a Nigerian teaching hospital. World Hosp Health Serv. 2012;48(1):31-4.

28. LamiFH,AlNaser RK. Epidemiological characteristics of burn injuries in Iraq: A burn hospital-based study. Burns 2o19;45(2): 479-483

29. He S, Zuo ZL Epidemiological investigation on 1 946 hospitalized pediatric patients with burns. Zhonghua Shao Shang ZaZhi. 2018 Oct 20; 34(10):696-700

30. Tripathee S, Basnet SJ .Epidemiology and outcome of hospitalized burns patients in tertiary care center in Nepal: Two year retrospective study. Burns Open 2017; 1(1): 16-19].

31. Karki B, Rai SM, Nakarmi KK, Basnet SJ, Magar MG, Nagarkoti KK, Thapa S. Clinical Epidemiology of Acute Burn Injuries at Nepal Cleft and Burn Centre, Kathmandu, Nepal 2018. Ann Plast Surg. 2018 Mar;80(3 Suppl 2):S95-S97.

32. Saaiq M, Ashraf B. Epidemiology and Outcome of Self-Inflicted Burns at Pakistan Institute of Medical Sciences, Islamabad. World J PlastSurg 2014;3(2):107-114.

33. Alhaider AKH, Hassan AJ, Hameed LM. Case Fatality Rate, Determination and Causes of Death in Al Nassiriay Burn Center at 2015 and 2016. ThiQar Medical Journal (TQMJ) 2018;15(1):30-42

34. Fathallah ZF. Epidemiological study of burn injuries in Basrah. Bas J Surg, 2005;11(1):60-66. 